\title{
Investigation of Pedestrian Crossing Behavior at Crossing Facilities in India
}

\author{
Atif Hussain*, Sanjeev Sinha \\ Department of Civil Engineering, National Institute of Technology Patna, Patna- 800005, Bihar, India
}

Received May 6, 2021; Revised June 22, 2021; Accepted July 19, 2021

\section{Cite This Paper in the following Citation Styles}

(a): [1] Atif Hussain, Sanjeev Sinha , "Investigation of Pedestrian Crossing Behavior at Crossing Facilities in India," Civil Engineering and Architecture, Vol. 9, No. 5, pp. 1442 - 1455, 2021. DOI: 10.13189/cea.2021.090517.

(b): Atif Hussain, Sanjeev Sinha (2021). Investigation of Pedestrian Crossing Behavior at Crossing Facilities in India. Civil Engineering and Architecture, 9(5), 1442 - 1455. DOI: 10.13189/cea.2021.090517.

Copyright $\odot 2021$ by authors, all rights reserved. Authors agree that this article remains permanently open access under the terms of the Creative Commons Attribution License 4.0 International License

\begin{abstract}
Pedestrians are one of the most vulnerable road users, yet requisite attention has not been given to their safety especially in developing countries. Every year large numbers of pedestrians are killed in road crashes in India, and many of them die while crossing the roads. The main aim of this paper is to investigate the crossing behavior of pedestrians \& to enhance road safety. The survey was conducted on 1423 participants. Factor analysis was carried out, which divided the pedestrian behaviors into five factors, namely: violation, lapse, error, risk, and infrastructure. Mann Whitney U test, Kruskal Wallis H test and post hoc test (Dunn's test with Bonferroni correction) were conducted to find the correlation between pedestrians' demographic features and behavioral factors. The results showed that the behavioral patterns like violations, lapses and risks are differentiated by gender. Men made statistically more violations, lapses and took more risks than female road users. Pedestrians from the low-income group, many of whom are devoid of formal education, showed more violations and risk-taking behavior compared to those from the higher-income group. Similarly, old road users and those coming from the higher-income group were found to be more concerned about the lack of pedestrian facilities.
\end{abstract}

Keywords Pedestrian, Crossing, Violation, Lapse, Error, Risks

\section{Introduction}

Safety of pedestrians is a major concern as they are the most vulnerable road users. A large number of pedestrians are either killed or injured while crossing roads. The study of pedestrian's attitudes and behavior can help to understand their requirements and development of policy measures to enhance their safety. Traffic accidents involving pedestrians mostly occur while they cross streets Antic et al. [1]. Large numbers of studies are carried out in countries like the USA, Serbia, Greece Antic, et al., Deb, et al.,Papadimitiou, et al. [1,2,3] using observational and survey techniques. Few studies have also been carried out in developing countries like India in metro cities like Bangalore and New Delhi Ravishankar \& Nair, Rankavat \& Tiwari, [4,5].

Contemporary literature on pedestrian crossing behavior depends on several factors. Study shows that large numbers of pedestrians $(65.7 \%)$ do not take a look at the vehicles while crossing streets Zhuang \& Wu, [6]. Also, $44 \%$ of pedestrians cross during the red signal of pedestrians Ni \& Li, [7]. Several researchers have carried out gender-based analysis of pedestrian crossing behavior. Male road users were observed to make more violations than their female counterparts (Ferenchak, Wu, et al., Shaaban, et al., Ravishankar \& Nair, [8,9,10,4]. Rankavat \& Tiwari [12] reported that there was less utilization of zebra crossing and underpasses by female road users. Lipovac et al. [11] concluded that larger number of females used crosswalks at the intersections having no signals than the one with installed signals. Also, the crossing speed of female users was found to be lesser than those of male users Marisamynathan \& Perumal, [12].

Apart from human factors, types of lanes, number of lanes, type of intersections and differences in cultures 
were also the important factors in determining the illegal crossing behavior of pedestrians Rastogi, et al., [13]. The design of pedestrian facilities also influences crossing behavior and its improper design discourages the pedestrian to cross at those locations Sisiopiku \& Akin, [14]. The most important pedestrian facility was found to be midblock crosswalks. Chandra et al., [15] studied the crossing behavior of pedestrians at various midblock crosswalks and analyzed the pattern of crossing, speed of crossing and the accepted gap during crossing. They concluded that the locations which serve heavy bi-directional traffic moving with improper lane discipline had higher average pedestrians' speed. The preference of shorter distance and to prevent collision with other pedestrians using the same crosswalk were the reasons behind the choice of the curved path of pedestrians Jamil, et al., [16]. An observational survey was conducted in Iran to identify the crossing behavior of pedestrian which concluded that individual characteristics, environmental conditions and traffic conditions affect the behavior of pedestrian Jahandideh et al. [17]. Observational as well as questionnaire survey was conducted to record the traffic as well as to take the response of the pedestrian respectively Arsandrie, et al., [18]. Three factors that cause traffic accidents include drunkenness, carelessness, and drowsiness. Moreover, high severity of traffic accidents in Ambon City was $91.95 \%$ caused by driver behavior factors observed by Leuhery et. al., [19]

Ages of pedestrians were also observed to be an important factor influencing their crossing behavior. Young pedestrians were found to be less cautious while crossing than the older one Antic, et al., [1] and they were also observed to make lesser use of crosswalks. They were found to be more prone to crashes with vehicles.

Regression analysis was used to validate the five-factor pedestrian behavior questionnaire Deb et al., [2]. Cantillo et al. [20] proposed a model to analyze the choice of pedestrians to cross the road where there were three alternatives available i.e. direct crossing, use of pedestrians' bridge and the crosswalk at signalized intersection. For urban roads, crossing behavior of pedestrians was modelled for finding out the accident risk Yannis, et al., [21]. A model was also developed to simulate the interaction between pedestrians and vehicles Wang, et al., [22]. Also, structural equation modelling was developed to evaluate the relationship between various factors and pedestrian crossing behavior Mo.Z.G. \& Mo.L.G [23]. Moreover, a technique was proposed to know the number and the points of crossings of pedestrian Papadimitiou et al., [3]. According to latest report released by Ministry of Road Transport and Highway (MORTH),
Government of India, total number of pedestrians killed in road accidents in India had increased from 15,746 in 2016 to 20,457 in 2017 , which was an increase of 29.9 percent and then increased up to 22,656 in 2018. Talking about the province of Bihar in India pedestrian accidents increased from 654 in 2016 to 1134 in 2017 and then substantially increased to 1445 in 2018 . The capital city of Patna was ranked fourth worst city in terms of road fatalities in 2016 (source: Union Ministry of Road Transport and Highway). Million plus city Patna recorded 52.4 deaths per 100 accidents in terms of severity of accident in 2016 and 34.8 in 2017 (in the urban area only). Data collected from local police stations (Patna city) also reveal that the pedestrian accidents during the crossing of the road had increased from 111 in 2016 to 143 in 2017 which further increased to 257 in 2018. Similar trends have been found in other midsized cities in India and other developing countries.

Most of the recent literature talks about crossing behavior in countries which are economically and technologically advanced. Limited studies have been conducted in developing countries. It has been found from literature survey that studies conducted in India mainly focussed on metropolitian cities like Delhi, Bangalore, and Mumbai. No studies have been conducted in million-plus midsized cities like Patna where walk share mode is 30.9\% (Comprehensive Mobility Plan 2018) [24]. Thus, there was a need to study about the pedestrians crossing behavior to analyze the different parameters that influence it and also for coming up with the policy measures to enhance safety for the pedestrians. Moreover, limited studies Yingying Ma et. al [25] have been conducted which considered income as a factor affecting pedestrian crossing behavior. This study also correlates income with pedestrian behavior.

The main objective of the paper is to examine the pedestrian crossing behavior at the existing pedestrian facilities and to suggest improvement measures to enhance road safety of these vulnerable road users.

\section{Material and Methods}

Patna is the capital of Bihar in India with an estimated population of 1.68 million. The population growth of Patna is $23.73 \%$ in 2011 which is expected to increase to 2.80 million by the year 2021 (Master Plan, 2016). In a total area of $136 \mathrm{~km}^{2}$ of Patna, the Patna municipal area is $99 \mathrm{~km}^{2}$, (CDP Patna, 2015).

The following figures depicting the behavior of pedestrians in Patna. 


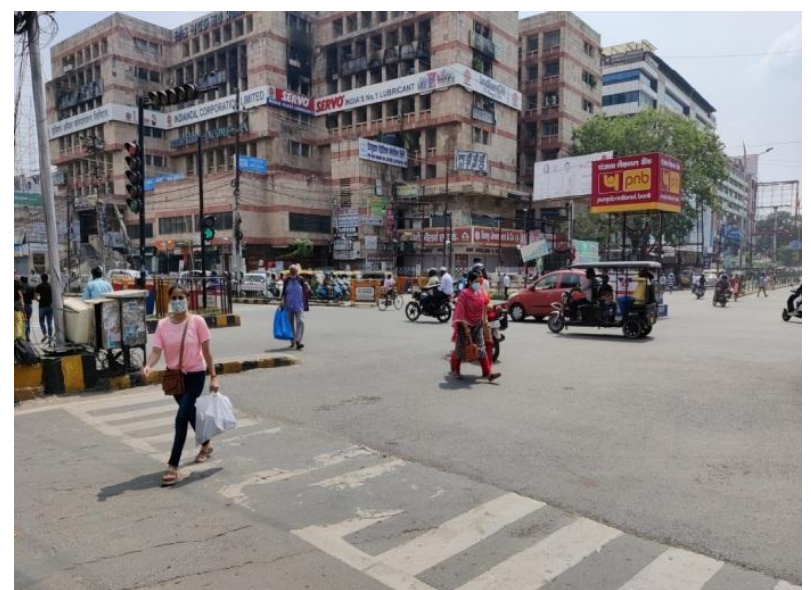

Figure 1. Road crossing diagonally

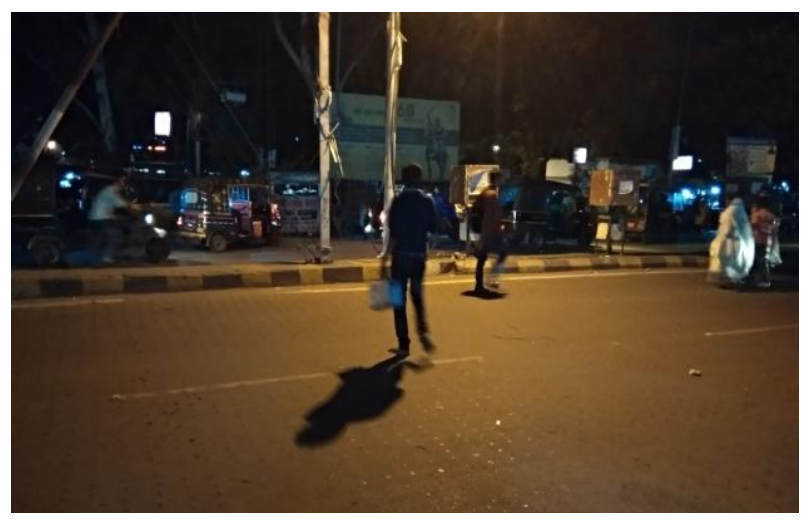

Figure 2. Lack of pedestrian facilities

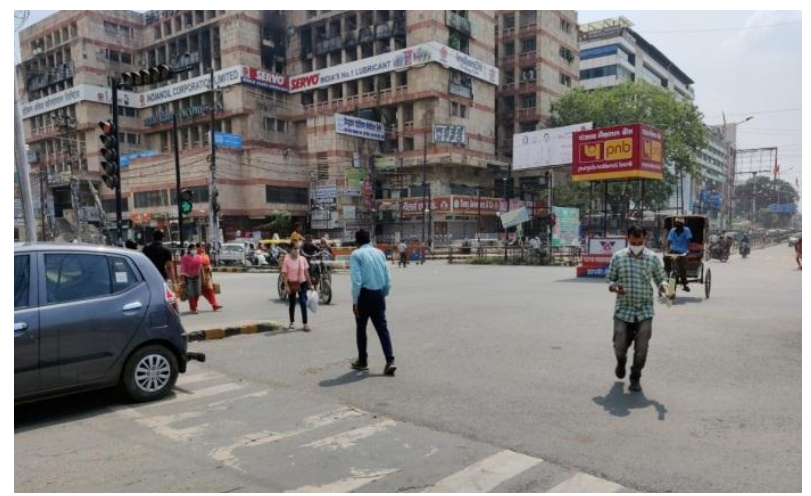

Figure 3. Pedestrians not using zebra crossing.

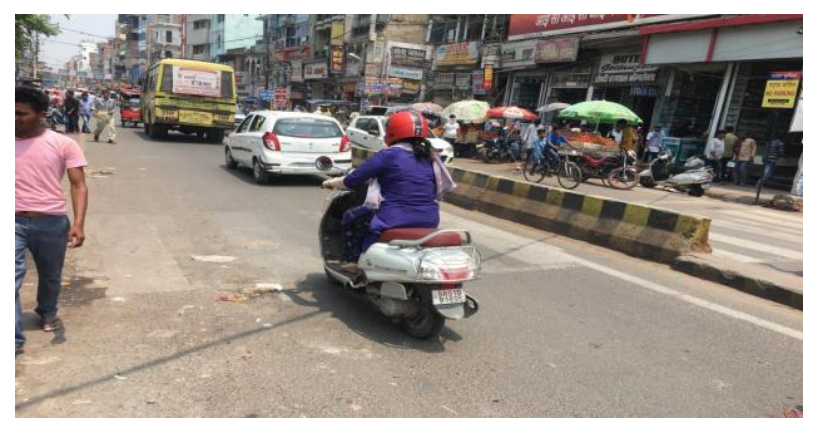

Figure 4. Showing the high median on zebra crossing.
The population growth has led to increased demand for infrastructural facilities which also includes facilities related to transportation infrastructure. Comprehensive Mobility Plan (CMP 2018) [24] for Patna reveals that walk share mode accounts for about $30.9 \%$. In spite of the high number of casualties on the city roads, the efforts taken for crash reduction have so far found to be inadequate.

In order to assess the pedestrian crossing behavior of the city, a questionnaire was designed and pedestrians were asked to give their responses on a 5-point Likert's scale for given 22 parameters. On-road face to face interview of users, college going students' interview and door to door surveys were incorporated to collect the database. A total of 1450 pedestrians were interviewed out of which 27 questionnaire forms were found to be incomplete. Therefore, a total of 1423 completed responses were used for the analysis.

The questionnaire consists of two parts. The first part describes the social and demographic features of pedestrians (age, gender, monthly income etc.). The second part describes the attitude and behavior of pedestrians while crossing. A total of 22 questions have been included which have been further divided into five groups (infrastructure, lapse, risk, violation and error). Likert scales with answers ranging from 1 to 5 , were used to answer the question, where the response 1 being 'Never' and 5 being 'Always'.

Principal component analysis (PCA) with varimax rotation and Eigen value greater than 1 was considered to determine factor structure of questionnaire. PCA analyses the structure by correlating among different variables into a common underlying dimension known as components or factors. The threshold of the statistical significance has been set to the conventional level of $\mathrm{P} \leq 0.05$.

Due to low factor loading $(<0.30)$ questions like 'How often do you cross at midblock when your company prompts you to do it', 'How often do you give priority to the pedestrian from the opposite direction when there is crowd at pedestrian crossing', 'How often do you intentionally move slowly while crossing the road in order to annoy driver', 'How often do you get angry at the driver who did not give you priority at the marked pedestrian crossing' and ' How often do you use the crosswalk (zebra crossing) when you see others do it', were not taken into consideration.

The collected data were examined in the statistical software package IBM SPSS V. 22. The non-parametric methods were used as the distribution of data was not found to be normal. Non-parametric analytical statistical methods (Mann-Whitney U test, Kruskal-Wallis test \& Dunn's test with Bonferroni correction) were used to analyse the statistical significance of association or difference, where appropriate. Mann-Whitney $U$ test is a statistical non-parametric technique used in statistics to understand the difference between two independent 
groups on continuous scale. The precondition in the application of Mann-Whitney $U$ test is that the variables should be characterized by the existence of two independent groups Laerd Statistics 2018, [26].

Kruskal Wallis $\mathrm{H}$ test is a non-parametric test which is used to differentiate statistically among two or more sets. Prior to use of this test, three assumptions should be satisfied. The first one is the dependent variable must be either continuous or ordinal. The second one is at least two groups should be defined for every independent variable. The third one is the observations within a group should be independent Laerd Statistics 2018, [27].

Kaiser-Meyer-Olkin (KMO) value determines the sample adequacy. Internal consistency of data was measured with the help of parameter known as Cronbach's alpha.

As Kruskal Wallis $\mathrm{H}$ test was conducted to confirm that whether the group's distribution was dissimilar or not from one another and the aggregate dataset but it does not give the information about which specific group of independent variables is statistically significantly different from each other. To understand this, Post hoc test (Dunn's test with Bonferroni Correction) was conducted.

Dunn's multiple comparison tests are a post hoc nonparametric test which can be used to pinpoint which specific means are more significant than the others. When conducting Dunn's multiple comparison test on the same dependent variable, the chance of committing error increases, thus increasing the likelihood of coming up with a significant result just by pure chance. To counteract this, a Bonferroni Correction is carried out. In statistics, a Bonferroni Correction is one of the several methods used to counteract the problem of multiple comparisons. Statistics how to 2020; Statistics solution 2020 [28, 29].

\section{Results}

This survey comprises of 1423 participants, out of all $840(59 \%)$ were male \& $583(41 \%)$ were female. The largest numbers of participants were of the age groups 18-25 and 25-35 years each having contributing of about $23 \%$ and $24 \%$ respectively. Similarly, respondents having their monthly income between Rs (INR) 20000-40000 (1 USD 72 INR) and between Rs (INR) 40000-60000 were the largest contributors of the survey, comprising of $30 \%$ and $29 \%$ of the total numbers of respondents respectively. This analyzed the effect of age, gender and monthly income on the crossing behavior of pedestrian. The users' demographic profiles are presented in the form of pie chart.

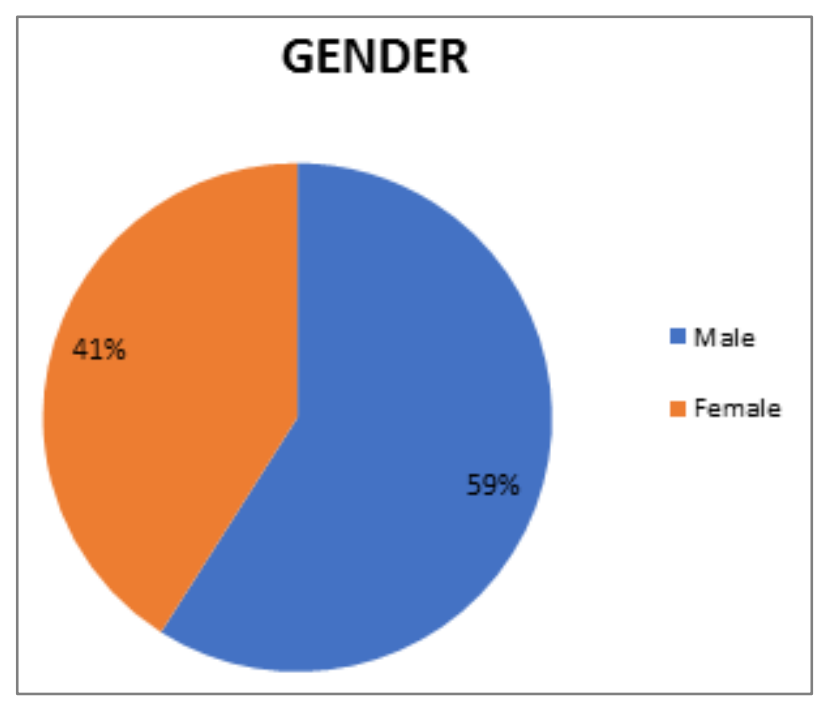

Figure 5. Pie chart represents gender

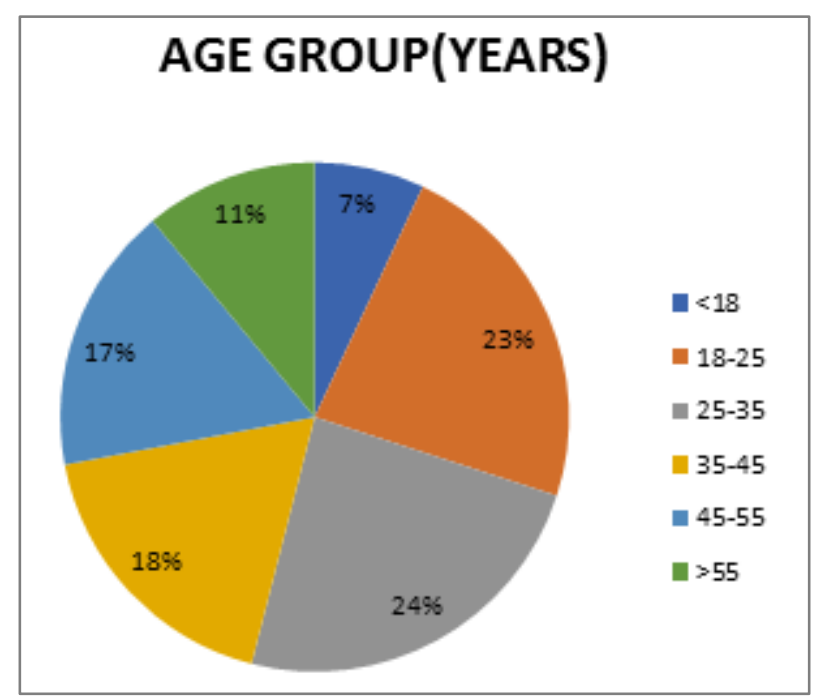

Figure 6. Pie chart represents participants of different age group

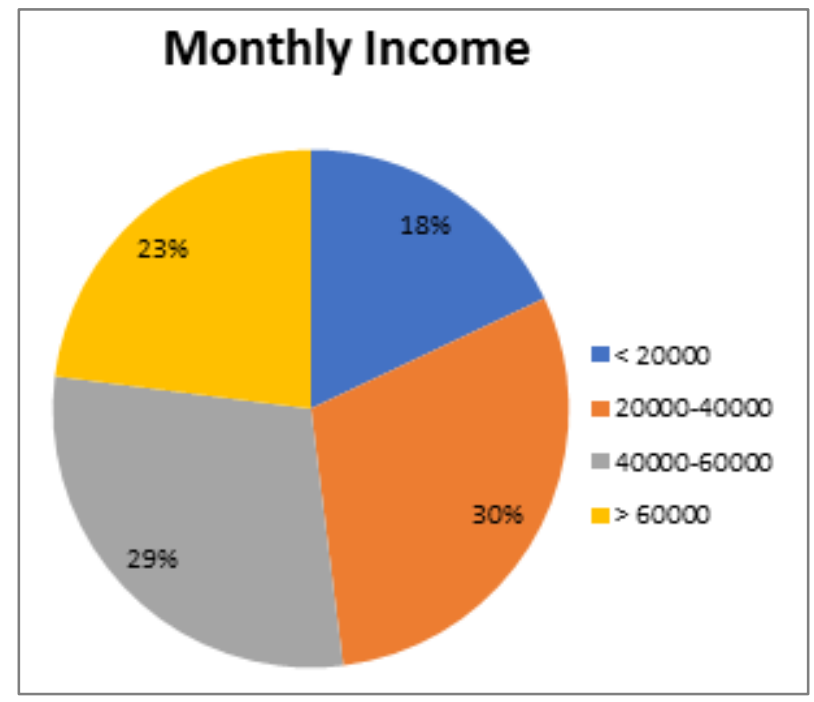

Figure 7. Pie chart represents monthly income (INR) of participants. 
Internal consistency and principal component analysis were determined considering the fact that this tool had never been used in Patna. Internal consistency was found to be fair (Cronbach's alpha 0.722) and the principal component analysis with orthogonal varimax rotation was carried out on all 22 parameters. The Scree plot resulting from factor analysis is best fitted for five factors. The five-factor solution has been presented in table 1 .

Factor 1 Infrastructure: Infrastructure is described by 5 questions in the questionnaire. Infrastructure was defined as lack of pedestrian facilities due to which results abnormal behavior while road crossing (eg: "shelter over midblock crosswalk influence your decision to cross at certain location", factor loading: 0.771).

Factor 2 Lapse: Lapse is described by 4 items in the questionnaire and was demonstrated as short failure of judgment (eg: "cross the road and did not look left and right because I was talking to a friend, factor loading 0.775).

Factor 3 Risk: Risk is described by 3 items in the questionnaire and can be explained as the behavior in which there are more chances of loss or injury (eg: "Cross between vehicles stopped on the roadway in traffic jams", factor loading 0.767).

Factor 4 Violation: Violation is described by 2 items in the questionnaire and is elaborated as the behavior in which rules are being disobeyed (eg: "cross the road diagonally in order to save time", factor loading 0.795).

Factor 5 Error: Error is described by 3 numbers of questions in the questionnaire. Error happened only when the decision taken by the pedestrian was wrong in road crossing (eg: "Cross at the designated location when there is a shop you like on the other side", factor loading 0.748 ).

From the Table 2, it can be reported that $47.49 \%$ of the participants selected 'always' and $26.00 \%$ selected 'often' in the question of "How often do the presence of pedestrian signal influence your decision to cross at certain locations". Hence it can be concluded that pedestrian of Patna gave a high level of importance towards the lack of pedestrian signals at many locations in the city.

It can also be seen that $36.17 \%$ of participants selected 'sometimes' and $22.22 \%$ selected 'Often' in the behavior of "How often do you cross at non-designated crosswalk". This shows that a large number of pedestrians are violating during road crossing.

It was observed in Patna that even during the red signal indication; vehicles crossed the stop line and occupy the crosswalks rather stopping before the stop line. Therefore, a question was added to know the behavior of pedestrians that whether they use the crosswalk when vehicles cross the stop line and occupy the crosswalk during red signal indication. Results indicate that $38.53 \%$ of participants selected 'Never' while $32.62 \%$ marked 'Rarely' which means people in Patna crosses the road in between the gap of vehicles when the traffic signal is red which becomes very risky as the traffic turns green. Table 2 shows the percentage of answer on the Likert scale from 1 (Never) to 5 (Always). 
Table 1. Factor analysis of 17 items (Varimax rotation)

\begin{tabular}{|c|c|c|c|c|c|}
\hline \multicolumn{6}{|c|}{ ROTATED COMPONENT MATRIX } \\
\hline \multirow[b]{2}{*}{ How often do the presence of/ how often do you } & \multicolumn{5}{|c|}{ Component } \\
\hline & $\begin{array}{c}1 \\
\text { Infrastructure } \\
\end{array}$ & $\begin{array}{c}2 \\
\text { Lapse } \\
\end{array}$ & $\begin{array}{c}3 \\
\text { Risk }\end{array}$ & $\begin{array}{c}4 \\
\text { Violation } \\
\end{array}$ & $\begin{array}{c}5 \\
5 \\
\text { Error }\end{array}$ \\
\hline $\begin{array}{l}\text { Shelter over mid-block crosswalk (zebra crossing) influences } \\
\text { your decision to cross at certain location. }\end{array}$ & 0.771 & & & & \\
\hline $\begin{array}{l}\text { Mid-block crosswalk (zebra crossing) influences your decision to } \\
\text { cross at certain location. }\end{array}$ & 0.735 & & & & \\
\hline $\begin{array}{l}\text { Pedestrian signal influences your decision to cross at certain } \\
\text { location. }\end{array}$ & 0.706 & & & & \\
\hline $\begin{array}{l}\text { Other pedestrians that attempt to cross-influence your decision to } \\
\text { cross at certain location. }\end{array}$ & 0.667 & & & & \\
\hline $\begin{array}{l}\text { Vegetation or barrier on median influences your decision to cross } \\
\text { at certain location. }\end{array}$ & 0.651 & & & & \\
\hline $\begin{array}{l}\text { Cross the road and did not look left and right because you were } \\
\text { talking to a friend. }\end{array}$ & & 0.775 & & & \\
\hline $\begin{array}{l}\text { Cross the road and did not look left and right because you were in } \\
\text { hurry. }\end{array}$ & & 0.738 & & & \\
\hline $\begin{array}{l}\text { Cross the road and did not look left and right because you were } \\
\text { thinking about something else. }\end{array}$ & & 0.713 & & & \\
\hline Use mobile phone while crossing the road. & & 0.686 & & & \\
\hline Cross between vehicles stopped on the roadway in traffic jams. & & & 0.767 & & \\
\hline $\begin{array}{l}\text { Start road crossing at the marked pedestrian crossing but finished } \\
\text { outside of it. }\end{array}$ & & & 0.734 & & \\
\hline $\begin{array}{l}\text { Use crosswalk (zebra crossing) when the vehicle crosses the stop } \\
\text { line and occupies the crosswalk. }\end{array}$ & & & 0.656 & & \\
\hline Cross the road diagonally in order to save time. & & & & 0.795 & \\
\hline Cross the road though the pedestrian light is red. & & & & 0.756 & \\
\hline $\begin{array}{l}\text { Cross at the designated location when there is a shop you like on } \\
\text { the other side. }\end{array}$ & & & & & 0.756 \\
\hline Cross the road at non-designated crosswalk (zebra crossing). & & & & & 0.685 \\
\hline $\begin{array}{l}\text { Cross even if vehicles are coming because you think they will } \\
\text { stop for me. }\end{array}$ & & & & & 0.493 \\
\hline Percent of explained variance in rotated sums of squared loadings & $20.5 \%$ & $13.7 \%$ & $11.5 \%$ & $8.2 \%$ & $10.4 \%$ \\
\hline
\end{tabular}


Table 2. Distribution of participant's responses

\begin{tabular}{|c|c|c|c|c|c|c|}
\hline \multirow{2}{*}{\multicolumn{2}{|c|}{ Item (How often do you. . .) }} & \multicolumn{5}{|c|}{ Answers to (\%) } \\
\hline & & $\begin{array}{c}\text { Never } \\
01 .\end{array}$ & $\begin{array}{c}\text { Rarely } \\
02 .\end{array}$ & $\begin{array}{c}\begin{array}{c}\text { Some } \\
\text { times }\end{array} \\
03 .\end{array}$ & $\frac{\text { Often }}{04 .}$ & $\frac{\text { Always }}{05 .}$ \\
\hline 01 & Cross the road even though the pedestrian light is red & 40.43 & 25.53 & 21.04 & 7.56 & 3.07 \\
\hline 02. & Cross the road diagonally in order to save time & 33.09 & 34.27 & 25.29 & 4.72 & 2.60 \\
\hline 03. & Use mobile phone while crossing the road & 44.92 & 22.45 & 17.02 & 9.92 & 3.30 \\
\hline 04. & Cross the road at non designated crosswalk (zebra crossing) & 14.18 & 21.75 & 36.17 & 22.22 & 5.67 \\
\hline 05. & $\begin{array}{l}\text { Cross the road and didn't look left \& right because you were thinking about } \\
\text { something else }\end{array}$ & 47.05 & 29.78 & 16.31 & 6.14 & 3.07 \\
\hline 06. & Cross the road and didn't look left and right because you were talking to a friend & 46.34 & 24.82 & 18.67 & 6.86 & 3.31 \\
\hline 07. & Cross the road and didn't look left and right because you were in a hurry & 10.17 & 24.59 & 36.87 & 17.49 & 10.87 \\
\hline 08. & Use crosswalk (zebra crossing) when you see others do it & 8.03 & 17.96 & 34.04 & 28.36 & 11.58 \\
\hline 09. & Cross at the designated location when there is a shop you like on the other side & 27.89 & 26.95 & 32.63 & 8.27 & 4.26 \\
\hline 10. & Cross even if vehicles are coming because you think that it will stop for you & 25.30 & 28.37 & 28.37 & 11.82 & 6.14 \\
\hline 11. & Cross between vehicles stopped on the roadway in traffic jams & 34.51 & 30.73 & 26.47 & 4.72 & 3.55 \\
\hline 12. & Start road crossing at the marked pedestrian crossing but finished outside of it & 29.07 & 30.26 & 24.59 & 11.34 & 4.72 \\
\hline 13. & $\begin{array}{l}\text { Use the crosswalk (zebra crossing) when the vehicle crosses the stop line and } \\
\text { occupies the crosswalk }\end{array}$ & 38.53 & 32.62 & 22.22 & 4.25 & 2.36 \\
\hline 14. & Intentionally move slowly while crossing the road in order to annoy driver & 35.46 & 20.09 & 12.05 & 4.73 & 4.25 \\
\hline 15. & $\begin{array}{c}\text { Get angry at the driver who didn't give you priority at the marked pedestrian } \\
\text { cro1ssing }\end{array}$ & 50.11 & 20.80 & 13.71 & 8.51 & 6.85 \\
\hline 16. & $\begin{array}{l}\text { Give priority to the pedestrian from the opposite direction when there is a crowd at } \\
\text { the pedestrian crossing }\end{array}$ & 6.85 & 12.76 & 30.96 & 30.02 & 19.38 \\
\hline 17. & Cross at midblock when your company prompts you to do it & 8.27 & 23.64 & 44.45 & 17.49 & 6.14 \\
\hline \multirow{3}{*}{\multicolumn{2}{|c|}{ Item (How often do the presence of. . .) }} & \multicolumn{5}{|c|}{ Distribution of responses } \\
\hline & & Never & Rarely & $\begin{array}{l}\text { Some } \\
\text { times }\end{array}$ & Often & Always \\
\hline & & 01. & 02. & 03. & 04. & 05. \\
\hline 18. & Pedestrian signal influences your decision to cross at certain location & 3.78 & 8.75 & 13.48 & 26.00 & 47.49 \\
\hline 19. & $\begin{array}{l}\text { Mid-block crosswalk (zebra crossing) influences your decision to cross at certain } \\
\text { location }\end{array}$ & 2.60 & 7.56 & 21.27 & 38.06 & 30.49 \\
\hline 20. & $\begin{array}{l}\text { Shelter over mid-block crosswalk (zebra crossing) influences your decision to } \\
\text { cross at certain location }\end{array}$ & 3.78 & 15.13 & 32.62 & 38.53 & 9.92 \\
\hline 21. & $\begin{array}{l}\text { Other pedestrians that attempt to cross-influence your decision to cross at certain } \\
\text { location }\end{array}$ & 5.20 & 20.56 & 49.40 & 20.33 & 4.49 \\
\hline 22. & $\begin{array}{l}\text { Vegetation or barriers on median influence your decision to cross at certain } \\
\text { location }\end{array}$ & 6.85 & 19.86 & 34.04 & 31.92 & 7.32 \\
\hline
\end{tabular}

\section{Association of gender with pedestrians' behavior}

Table 3 describes the statistical comparison of the frequency of certain crossing behavior of pedestrian with gender. Male made statistically more violations $(\mathrm{Z}=$ -2.604, $\mathrm{P}=0.009)$, lapses $(\mathrm{Z}=-3.209, \mathrm{P}=0.000)$ in comparison to female. Whereas, the error $(\mathrm{Z}=-0.869, \mathrm{P}=$ $0.389)$ and the infrastructure $(\mathrm{Z}=-0.481, \mathrm{P}=0.630)$ are not statistically significantly differentiated between gender.

\section{Association of age with pedestrian behavior}

From Table 4 it can be seen that age is significantly positively associated with violation, lapse, error, risk and infrastructure (P-value is less than 0.05 in all cases).

Dunn's test with Bonferroni correction was used to identify the role of age group on factors (Table $5 \& 6$ ).

Age groups in the range of 18-25 years \& $<18$ years are statistically more violating as compared to the age group of greater than 55 years (Adjusted p-value less than 0.05). Pedestrians belonging to the age group $<18$ years, $18-25$ years, 25-35 years, 35-45 years, and 45-55 years are statistically causing lesser lapses in comparison to the pedestrian having age greater than 55 years (Adjusted $\mathrm{p}$-value less than 0.05).

Pedestrian belonging to the age group between 18-25 years was observed to cause more errors as compared to 
the age group greater than 55 years (Adjusted p-value less than 0.05). Whereas, pedestrian belonging to age group $<18$ years, 18-25 years, 25-35 years,35-45 years, and 45-55 years are statistically taking more risks than the age group greater than 55 years. Also, pedestrian belonging to age group 18-25 years took more risks than those from age groups 35-45 years \& 45-55 years (Adjusted p-value less than 0.05).

Pedestrians having age greater than 55 years were more demanding for pedestrian facilities comparison to other age groups. Also, the concern of lack of pedestrian facilities is more for ages between $35 \& 45$ years in comparison to 25-35 years (Adjusted p-value less than $0.05)$.

Table 3. Gender and pedestrians' behavior

\begin{tabular}{|c|c|c|c|c|c|c|c|}
\hline \multicolumn{3}{|c|}{ GENDER } & VIOLATION & LAPSE & ERROR & RISK & INFRASTRUCTURE \\
\hline \multirow{3}{*}{ FEMALE } & \multicolumn{2}{|c|}{ Median } & 1.500 & 1.000 & 3.000 & 2.000 & 3.000 \\
\hline & \multirow{2}{*}{ Percentiles } & 25 & 1.000 & 1.000 & 2.000 & 1.000 & 3.000 \\
\hline & & 75 & 2.500 & 2.000 & 3.000 & 3.000 & 4.000 \\
\hline \multirow{3}{*}{ MALE } & \multicolumn{2}{|c|}{ Median } & 2.000 & 1.500 & 3.000 & 3.000 & 4.000 \\
\hline & \multirow{2}{*}{ Percentiles } & 25 & 1.000 & 1.000 & 2.000 & 1.000 & 3.000 \\
\hline & & 75 & 3.000 & 3.000 & 3.000 & 3.000 & 4.000 \\
\hline $\begin{array}{c}\text { Mann-Whitney } \\
\text { U test }\end{array}$ & $\begin{array}{l}\mathrm{Z} \\
\mathrm{P}\end{array}$ & & $\begin{array}{c}-2.064 \\
0.009\end{array}$ & $\begin{array}{l}-3.209 \\
0.001\end{array}$ & $\begin{array}{c}-0.861 \\
0.389 \\
\end{array}$ & $\begin{array}{c}-3.977 \\
0.000\end{array}$ & $\begin{array}{c}-0.481 \\
0.630\end{array}$ \\
\hline
\end{tabular}

Table 4. Association of age and pedestrian behavior

\begin{tabular}{|c|c|c|c|c|c|c|c|}
\hline \multicolumn{3}{|c|}{ Age group (years) } & \multirow{2}{*}{$\frac{\text { Violation }}{2.250}$} & \multirow{2}{*}{$\begin{array}{l}\text { Lapse } \\
2.250\end{array}$} & \multirow{2}{*}{$\frac{\text { Error }}{2.500}$} & \multirow{2}{*}{$\frac{\text { Risk }}{2.500}$} & \multirow{2}{*}{$\frac{\text { Infrastructure }}{3.000}$} \\
\hline & Median & & & & & & \\
\hline$<18$ & Percentile & $\begin{array}{l}25 \\
75\end{array}$ & $\begin{array}{l}1.500 \\
3.500\end{array}$ & $\begin{array}{l}1.000 \\
3.625\end{array}$ & $\begin{array}{l}2.000 \\
3.000 \\
\end{array}$ & $\begin{array}{l}2.000 \\
4.000\end{array}$ & $\begin{array}{l}3.000 \\
4.000\end{array}$ \\
\hline \multirow[b]{2}{*}{$18-25$} & Median & & 2.500 & 2.000 & 3.000 & 3.000 & 3.000 \\
\hline & Percentile & $\begin{array}{l}25 \\
75 \\
\end{array}$ & $\begin{array}{l}1.500 \\
3.500 \\
\end{array}$ & $\begin{array}{l}1.000 \\
3.500 \\
\end{array}$ & $\begin{array}{l}2.000 \\
3.000 \\
\end{array}$ & $\begin{array}{l}2.000 \\
3.000 \\
\end{array}$ & $\begin{array}{l}3.000 \\
4.000 \\
\end{array}$ \\
\hline \multirow[b]{2}{*}{$25-35$} & Median & & 1.750 & 2.000 & 3.000 & 3.000 & 3.000 \\
\hline & Percentile & $\begin{array}{l}25 \\
75 \\
\end{array}$ & $\begin{array}{l}1.000 \\
2.500\end{array}$ & $\begin{array}{l}1.000 \\
3.000 \\
\end{array}$ & $\begin{array}{l}2.000 \\
3.000 \\
\end{array}$ & $\begin{array}{l}1.750 \\
3.000 \\
\end{array}$ & $\begin{array}{l}3.000 \\
4.000\end{array}$ \\
\hline \multirow[b]{2}{*}{$35-45$} & Median & & 1.500 & 1.750 & 2.500 & 2.000 & 4.000 \\
\hline & Percentile & $\begin{array}{l}25 \\
75 \\
\end{array}$ & $\begin{array}{l}1.000 \\
2.500\end{array}$ & $\begin{array}{l}1.000 \\
3.000 \\
\end{array}$ & $\begin{array}{l}2.000 \\
3.000 \\
\end{array}$ & $\begin{array}{l}1.000 \\
3.000 \\
\end{array}$ & $\begin{array}{l}3.000 \\
4.000\end{array}$ \\
\hline \multirow[b]{2}{*}{$45-55$} & Median & & 1.500 & 1.500 & 2.000 & 2.000 & 4.000 \\
\hline & Percentile & $\begin{array}{l}25 \\
75\end{array}$ & $\begin{array}{l}1.000 \\
2.000\end{array}$ & $\begin{array}{l}1.000 \\
2.000\end{array}$ & $\begin{array}{l}1.000 \\
3.000 \\
\end{array}$ & $\begin{array}{l}1.000 \\
3.000 \\
\end{array}$ & $\begin{array}{l}3.000 \\
4.000\end{array}$ \\
\hline \multirow[b]{2}{*}{$\begin{array}{c}>55 \\
\text { Kruskal } \\
\text { Wallis H } \\
\text { test }\end{array}$} & Median & & 1.000 & 1.000 & 1.500 & 1.500 & 4.000 \\
\hline & Percentile & $\begin{array}{l}25 \\
75\end{array}$ & $\begin{array}{l}1.000 \\
1.500 \\
0.000\end{array}$ & $\begin{array}{l}1.000 \\
1.000 \\
0.000\end{array}$ & $\begin{array}{l}1.000 \\
2.000 \\
0.000\end{array}$ & $\begin{array}{l}1.000 \\
3.000 \\
0.000\end{array}$ & $\begin{array}{l}4.000 \\
5.000 \\
0.000\end{array}$ \\
\hline
\end{tabular}


Table 5. Multiple comparisons of age with pedestrian behavior (Dunn's test with Bonferroni correction).

\begin{tabular}{|c|c|c|}
\hline $\begin{array}{c}\text { Age group (years) } \\
\text { Sample1 \& Sample } 2\end{array}$ & \multicolumn{2}{|c|}{ Violation } \\
\hline \multirow{2}{*}{$>55 \& 18-25$} & $\mathrm{P}$-value & Adjusted $\mathrm{p}$ value $\mathrm{a}^{\mathrm{a}}$ \\
\hline & .000 & .001 \\
\hline \multirow[t]{3}{*}{$>55 \&<18$} & .002 & .028 \\
\hline & \multicolumn{2}{|c|}{ Lapse } \\
\hline & P-value & Adjusted $\mathrm{p}$ value $\mathrm{a}^{\mathrm{a}}$ \\
\hline$>55 \& 45-55$ & .000 & .001 \\
\hline$>55 \& 35-45$ & .000 & .000 \\
\hline$>55 \& 25-35$ & .000 & .000 \\
\hline$>55 \&<18$ & .000 & .000 \\
\hline \multirow[t]{3}{*}{$>55 \& 18-25$} & .000 & .000 \\
\hline & \multicolumn{2}{|c|}{ Error } \\
\hline & P-value & Adjusted $\mathrm{p}$ value $\mathrm{a}^{\mathrm{a}}$ \\
\hline \multirow[t]{3}{*}{$>55 \& 18-25$} & .001 & .023 \\
\hline & \multicolumn{2}{|c|}{ Risk } \\
\hline & P-value & Adjusted $\mathrm{p}$ value $\mathrm{a}^{\mathrm{a}}$ \\
\hline$>55 \& 45-55$ & .000 & .000 \\
\hline$>55 \& 35-45$ & .000 & .000 \\
\hline$>55 \& 25-35$ & .000 & .000 \\
\hline$>55 \&<18$ & .000 & .000 \\
\hline$>55 \& 18-25$ & .000 & .000 \\
\hline $35-45 \& 18-25$ & .000 & .002 \\
\hline \multirow[t]{3}{*}{$45-55 \& 18-25$} & .002 & .028 \\
\hline & \multicolumn{2}{|c|}{ Infrastructure } \\
\hline & P-value & Adjusted $\mathrm{p}$ value $\mathrm{a}^{\mathrm{a}}$ \\
\hline $25-35 \& 35-45$ & .002 & .037 \\
\hline $25-35 \&>55$ & .000 & .000 \\
\hline $18-25 \&>55$ & .000 & .000 \\
\hline$<18 \&>55$ & .000 & .000 \\
\hline $45-55 \&>55$ & .000 & .001 \\
\hline $35-45 \&>55$ & .000 & .004 \\
\hline
\end{tabular}

Significance values have been adjusted by the Bonferroni correction for multiple tests. 
Table 6. Association of age group with mean rank.

\begin{tabular}{|c|c|c|}
\hline \multirow{7}{*}{ Violation } & Age group (years) & Mean rank \\
\hline & $<18$ & 828.56 \\
\hline & $18-25$ & 811.39 \\
\hline & $25-35$ & 689.33 \\
\hline & $35-45$ & 675.63 \\
\hline & $45-55$ & 712.70 \\
\hline & $>55$ & 533.84 \\
\hline \multirow{6}{*}{ Lapse } & $<18$ & 777.47 \\
\hline & $18-25$ & 806.05 \\
\hline & $25-35$ & 734.95 \\
\hline & $35-45$ & 730.58 \\
\hline & $45-55$ & 700.50 \\
\hline & $>55$ & 412.83 \\
\hline \multirow{6}{*}{ Error } & $<18$ & 601.98 \\
\hline & $18-25$ & 683.79 \\
\hline & $25-35$ & 657.54 \\
\hline & $35-45$ & 740.67 \\
\hline & $45-55$ & 776.08 \\
\hline & $>55$ & 818.52 \\
\hline \multirow{6}{*}{ Risk } & $<18$ & 917.03 \\
\hline & $18-25$ & 877.19 \\
\hline & $25-35$ & 740.65 \\
\hline & $35-45$ & 642.74 \\
\hline & $45-55$ & 686.70 \\
\hline & $>55$ & 319.94 \\
\hline \multirow{6}{*}{ Infrastructure } & $<18$ & 631.62 \\
\hline & $18-25$ & 639.07 \\
\hline & $25-35$ & 595.98 \\
\hline & $35-45$ & 779.73 \\
\hline & $45-55$ & 738.57 \\
\hline & $>55$ & 631.62 \\
\hline
\end{tabular}

\section{Association of monthly income with pedestrian behavior}

Table 7 demonstrates that monthly income is significantly positively associated with violation, lapse, risk and infrastructure (P-value $<0.05)$. While error is not significantly associated with monthly income

By performing Dunn's test with Bonferroni correction, it can be used to identify the role of monthly income of the pedestrians on crossing behavior (Table $8 \& 9$ ).

Pedestrians having income < Rs20000, Rs 20000-40000, and Rs 40000-60000 are statistically causing more violation in comparison to income group greater than Rs 60000(Adjusted p-value less than 0.05).
Pedestrian belonging to the income group Rs 20000-40000 showing lesser number of lapses than the income group belongs to the category of Rs 40000-60000 $\&>$ Rs 60000(Adjusted p-value less than 0.05).

Low income group pedestrian (Rs 20000-40000) is taking more risk than high income group pedestrian (> Rs 60000) (Adjusted p-value less than 0.05).

Pedestrian having income in the range of Rs 40000-60000 \& > Rs 60000 demands more pedestrian infrastructural facilities in comparison to the income group less than Rs 20000 \& Rs 20000-40000 (Adjusted p-value less than 0.05). 
Table 7. Association of Monthly income and pedestrian behavior

\begin{tabular}{|c|c|c|c|c|c|c|c|}
\hline \multicolumn{3}{|c|}{ Monthly income (in rupees) } & Violation & Lapse & Error & Risk & Infrastructure \\
\hline \multirow[b]{2}{*}{$<20000$} & Median & & 2.000 & 2.000 & 3.000 & 3.000 & 3.000 \\
\hline & Percentile & $\begin{array}{l}25 \\
75 \\
\end{array}$ & $\begin{array}{l}1.500 \\
2.750 \\
\end{array}$ & $\begin{array}{l}1.000 \\
3.000 \\
\end{array}$ & $\begin{array}{l}2.000 \\
3.000 \\
\end{array}$ & $\begin{array}{l}2.000 \\
4.000 \\
\end{array}$ & $\begin{array}{l}2.000 \\
3.000 \\
\end{array}$ \\
\hline \multirow[b]{2}{*}{$20000-40000$} & Median & & 2.000 & 2.500 & 2.000 & 3.000 & 3.000 \\
\hline & Percentile & $\begin{array}{l}25 \\
75 \\
\end{array}$ & $\begin{array}{l}1.000 \\
3.000 \\
\end{array}$ & $\begin{array}{l}1.000 \\
3.000 \\
\end{array}$ & $\begin{array}{l}2.000 \\
3.000 \\
\end{array}$ & $\begin{array}{l}2.000 \\
3.000 \\
\end{array}$ & $\begin{array}{l}3.000 \\
4.000 \\
\end{array}$ \\
\hline \multirow[b]{2}{*}{$40000-60000$} & Median & & 1.500 & 1.000 & 2.000 & 2.000 & 4.000 \\
\hline & Percentile & $\begin{array}{l}25 \\
75 \\
\end{array}$ & $\begin{array}{l}1.000 \\
2.000 \\
\end{array}$ & $\begin{array}{l}1.000 \\
2.500 \\
\end{array}$ & $\begin{array}{l}2.000 \\
3.000 \\
\end{array}$ & $\begin{array}{l}1.000 \\
3.000 \\
\end{array}$ & $\begin{array}{l}3.000 \\
4.000 \\
\end{array}$ \\
\hline \multirow[b]{2}{*}{$\begin{array}{c}>60000 \\
\text { Kruskal } \\
\text { Wallis H test }\end{array}$} & Median & & 1.500 & 1.000 & 2.000 & 2.000 & 4.000 \\
\hline & Percentile & $\begin{array}{l}25 \\
75\end{array}$ & $\begin{array}{l}1.000 \\
2.000 \\
0.000 \\
\end{array}$ & $\begin{array}{l}1.000 \\
2.000 \\
\\
0.000 \\
\end{array}$ & $\begin{array}{l}1.000 \\
3.000 \\
0.188 \\
\end{array}$ & $\begin{array}{l}1.000 \\
3.000 \\
\\
0.000 \\
\end{array}$ & $\begin{array}{l}3.000 \\
4.000 \\
\\
0.000 \\
\end{array}$ \\
\hline
\end{tabular}

Table 8. Multiple comparisons of monthly income with pedestrian behavior (Dunn's test with Bonferroni correction).

\begin{tabular}{|c|c|c|}
\hline $\begin{array}{c}\text { Monthly income (in Rupee) } \\
\text { Sample } 1 \text { \& Sample } 2 \\
\end{array}$ & \multicolumn{2}{|c|}{ Violation } \\
\hline \multirow{2}{*}{$>60000 \& 40000-60000$} & P-value & Adjusted $\mathrm{p}$ value \\
\hline & .003 & .020 \\
\hline$>60000 \& 20000-40000$ & .000 & .000 \\
\hline \multirow[t]{3}{*}{$>60000 \&<20000$} & .001 & .004 \\
\hline & \multicolumn{2}{|c|}{ Lapse } \\
\hline & P-value & Adjusted $\mathrm{p}$ value \\
\hline$>60000 \& 20000-40000$ & .000 & .000 \\
\hline \multirow[t]{3}{*}{$40000-60000 \& 20000-40000$} & .001 & .004 \\
\hline & \multicolumn{2}{|c|}{ Risk } \\
\hline & P-value & Adjusted $\mathrm{p}$ value \\
\hline \multirow[t]{3}{*}{$>60000 \& 20000-40000$} & .000 & .001 \\
\hline & \multicolumn{2}{|c|}{ Infrastructure } \\
\hline & P-value & Adjusted $\mathrm{p}$ value \\
\hline$<20000 \& 40000-60000$ & .000 & .001 \\
\hline$<20000 \&>60000$ & .000 & .001 \\
\hline $20000-40000 \& 40000-60000$ & .006 & .035 \\
\hline $20000-40000 \&>60000$ & .003 & .015 \\
\hline
\end{tabular}

a. Significance values have been adjusted by the Bonferroni correction for multiple tests.

Table 9. Association of monthly income with mean rank.

\begin{tabular}{|c|c|c|}
\hline \multirow{4}{*}{ Violation } & Monthly income (Rupees) & Mean rank \\
\cline { 2 - 3 } & $<20000$ & 887.32 \\
\cline { 2 - 3 } & $20000-40000$ & 801.68 \\
\cline { 2 - 3 } & $40000-60000$ & 701.26 \\
\cline { 2 - 3 } & $>60000$ & 546.64 \\
\hline \multirow{4}{*}{ Lapse } & $<20000$ & 832.19 \\
\cline { 2 - 3 } & $20000-40000$ & 817.08 \\
\cline { 2 - 3 } & $40000-60000$ & 661.02 \\
\cline { 2 - 3 } & $>60000$ & 596.63 \\
\hline \multirow{4}{*}{ Risk } & $<20000$ & 767.22 \\
\cline { 2 - 3 } & $20000-40000$ & 781.30 \\
\cline { 2 - 3 } & $40000-60000$ & 697.26 \\
\cline { 2 - 3 } & $>60000$ & 610.73 \\
\hline \multirow{4}{*}{ Infrastructure } & $<20000$ & 449.01 \\
\cline { 2 - 3 } & $20000-40000$ & 658.08 \\
\hline & $40000-60000$ & 757.67 \\
\cline { 2 - 3 } & $>60000$ & 780.90 \\
\hline
\end{tabular}




\section{Discussions}

This study examines the pedestrian crossing behavior at various pedestrian facility locations. Variance explained by factor analysis should not be less than $60 \%$ Hair J.F,[30]. The scree plot showed that the data are best fitted for the five-factor solution, which accounted for $64.3 \%$ of the total variance. A factor analysis was carried out which identified five axes namely violation, error, lapse, risk and infrastructure.

Results of this study showed the distinction between violations, errors, lapses, infrastructures \& risks. Thus, it is different from the previous studies like the Serbian version of pedestrian behavior scale (PBS) which showed the distinction between violations, errors \& lapses Antic, et al., [1] The participants of pedestrian behavior study in France didn't distinguish between violations \& errors Granie, et al., [31]. On the other hand, the participants in Turkey did not differentiate between error \& lapses as reported by Yildirim, [32].

Pedestrian in Patna, India gave a high level of importance to the requirements of pedestrian signals. Hence it can be suggested that pedestrian signals should be installed at the locations where pedestrian volume is high. A large number of pedestrians are crossing at non-designated locations, it can be suggested that pedestrian facilities should be provided on those locations. Also, the younger pedestrians are more violating and taking more risks than the older. Therefore an awareness program should be launched to educate the younger about pedestrian behavior on different platforms like the internet, television, posters, etc. Also, traffic rules should be enforced properly to improve the crossing behavior of pedestrians. There is a need to widen pedestrian refuge island to be utilized by pedestrians in large numbers.

The association of age, gender and Monthly income with pedestrian crossing behavior was also examined.

\subsection{Comparison by Gender}

The study showed that male and female have some differences in their crossing behavior. Males show more numbers of violations, lapses and take more risks as compared to females. These results were obvious because of gender differences in society and have also been confirmed by other studies Antic, et al., Granie, et al., $[1,31]$. These results prove that unlike male, females are more careful while crossing the road. Females were observed to obey traffic rules and regulations more than males.

\subsection{Comparison by Age}

Age is statistically significantly related with all the five different pedestrian behaviors (since the P-value is less than 0.05 in all cases). The result showed that age group
$<18$ years \& $18-25$ years are more violating in comparison to older pedestrians ( $>55$ years). The confirmation of results has been found in the study of Antic, et al., [1], where younger pedestrians showed more violation than older pedestrians. Similar results were observed by Yildrim [32], who concluded that the increase in age led to the reduction in violations by drivers \& pedestrians. The highest number of lapses was found by younger pedestrian while the older pedestrians were causing more error than younger. This dissimilarity of results with Antic, et al., [1] was because of different socio-cultural, educational and awareness levels prevailing in both the study areas.

\subsection{Comparison by Monthly Income}

Monthly income is statistically significantly associated with all pedestrian behaviors $(p<0.05)$ except the factor like error ( $p>0.05)$. The result showed that higher income group pedestrian showing least violation than the low income group pedestrian. This result was dissimilar to the study Yingying Ma et. al [25] as there was no such significant effect found in between income and violation. Low income group of pedestrians was observed to have more lapses and take more risks than the high income group pedestrians. While the higher income group pedestrians observed to be more demanding for pedestrian facilities than the low-income group pedestrian, because of higher awareness about their citizenship's rights.

\section{Conclusions}

Pedestrians are vulnerable to road accidents and every year large number of pedestrians are killed due to it. The pedestrian street crossing behavior is complex and has often led to traffic crashes or accidents.

The present study tried to investigate the behavior of pedestrian and to suggest measures to enhance road safety. A Pedestrian Behavior Questionnaire (PBQ) was developed to study the behavior of pedestrian in the city of Patna, India and also the demographic profile of the pedestrians was included in it.

Factor analysis was conducted and it divided the pedestrian behavior into five factors which include violation, error, lapse, risk, and infrastructure. A violation was defined as an intentional deviation from the legal rules guiding pedestrian behavior. Errors were defined as making decisions that put the pedestrian in danger, without disobeying the legal rules. Lapses were defined as ill-suited behaviors related to lack of concentration on the task. Risk was defined as a situation involving exposure to danger. Infrastructure was defined as the lack of crossing facilities for pedestrians. Data were found to be reliable as Cronbach's Alpha value came to be 0.722 which is greater than 0.7 . 
Based on the results obtained it can be concluded that male made more violation causing lapse and took more risks than female. Also, the error and infrastructure are not differentiated by genders. It can also be concluded that young pedestrians are more violating and are taking more risk than other age groups. Pedestrians having age 35-45 $\&$ greater than 55 years are more demanding for the need of pedestrian facilities. Pedestrian's facilities like installation of signals have been given a primary concern by pedestrians in Patna especially by older age and higher income group pedestrian.

The older, as well as high income group pedestrians were observed to be least violating of traffic rules and took minimum risk. It was also observed that low income group pedestrians are more violating, have more lapses and took more risks as compared to high income group pedestrians.

The results of the present study shall be useful for ameliorating pedestrian facilities and reduction in fatalities and injuries of pedestrian in urban agglomeration of Patna, India. As many of other urban agglomeration face similar situations (53 numbers), the results of the present study shall be applied to other agglomerations of India and cities of other developing countries.

\section{Acknowledgements}

Authors would like to express their deepest sense of gratitude to the team of National Institute of Technology Patna, India who carried out the work of preparation of Comprehensive Mobility Plan for Patna for helping us in data collection and accepting the recommendations of it in principle to be incorporated in the revised (Comprehensive Mobility Plan 2018).

\section{REFERENCES}

[1] Antic, B., Pesic, D., Milutinovic, N. \& Maslac, M., " Pedestrian behaviors: Validation of the Serbian version of the pedestrian behavior scale". Transportation Research Part F, pp. 170-178,2016,DOI: 10.1016/j.trf.2016.02.004

[2] Shuchisnigdha Deb, Lesley Strawderman, Janice DuBien, Brian Smith, Daniel W. Carruth, Teena M. Garrison,"Evaluating pedestrian behavior at crosswalks: Validation of pedestrian behavior questionnaire for the U.S. population". Accident Analysis and Prevention, 106, 191-201, 2017, DOI: 10.1016/j.aap.2017.05.020

[3] Papadimitiou, E., Yannis, G. \& Golias, J.,"Theoretical framework for modelling pedestrians' crossing behavior along a trip". Journal of transportation engineering, 136(10), 914-924, 2010, DOI: 10.1061/(ASCE)TE.1943-5 436.0000163 .

[4] Ravishankar K. V. R., Nair, P. M.,"Pedestrian risk analysis at uncontrolled midblock and unsignalised intersections".
Traffic and Transportation Engineering, 137-147, 2018, DOI: 10.1016/j.jtte.2017.06.005.

[5] Rankavat, S. \& Tiwari, G.,"Pedestrians perceptions for utilization of pedestrian facilities- Delhi, India". Transportation Research Part F: Traffic Psychology and Behavior, 495-499, 2016, DOI: 10.1016/j.trf.2016.02.005

[6] Zhuang X., Wu C.,"Pedestrians' crossing behavior and safety at unmarked roadway in china". Accident Analysis and Prevention, 43, 1927-1936, 2011, DOI: 10.1016/j.aap.2011.05.005

[7] NI Y., LI K.,"Modelling pedestrian behavior at signalized intersection: a case study in Shanghai". First International Conference on Transportation Information and Safety, 1745-1754, 2011.

[8] Ferenchak N. N.,"Pedestrian age and gender in relation to crossing behavior at midblock crossing". TRAFFIC AND TRANSPORTATION ENGINEERING, 2(4), 345-351, 2016, DOI: $10.1016 /$ j.jtte.2015.12.001

[9] Wu Y., Lu J., Chen Y., Zhou J.,"Evaluation of Pedestrians crossing Behavior at Crosswalks by age and gender". 17th COTA International Conference of Transportation Professionals, 4220-4229, 2017.

[10] Shaaban K., Muley D., Mohammed A.,"Analysis of illegal pedestrian crossing behavior on major divided arterial road". Transportation Research Part F, 54, 124-137, 2018, DOI: 10.1016/j.trf.2018.01.012

[11] Lipovac K., Vujanic M., Maric B., Nesic M.,"Pedestrian Behavior at Signalized Pedestrian Crossings". Journal of Transportation Engineering, 139(2), 165-172, 2013, DOI: 10.1061/(ASCE)TE.1943-5436.0000491

[12] Marisamynathan, Perumal V.,"Study on Pedestrian Crossing Behavior at Signalized Intersections". 14th COTA International Conference of Transportation Professionals, 103-110, 2014.

[13] Rastogi R., Chandra S., Vamsheedhar J., Das V. R.,"Parametric Speed of Pedestrian Speed at Midblock Crossing". Journal of Urban Planning and Development, 137(4), 381-389, 2011, DOI: 10.1061/(ASCE)UP.1943-54 44.0000083

[14] Sisiopiku V. P., Akin D.,"Pedestrian behaviors at and perceptions towards various pedestrian facilities: an examination based on observation and survey data". Transportation Research Part F, 6,249-274, 2003, DOI: 10.1016/j.trf.2003.06.001

[15] Chandra, S., Rastogi R., Das V. R.,"Crossing behavior of pedestrians at midblock in mixed traffic". Journal of Indian road congress, 593-604, 2013.

[16] Rolla Jamil, Shengwu Xiong, Xiangzhen Kong, Senwen Zheng, Zhixiang Fang,"Pedestrian crossing patterns preference at non-signalized crosswalk". 6th International Conference on Applied Human Factors and Ergonomics (AHFE 2015) and the Affiliated Conferences, 3, 3353-3359, DOI: 10.1016/j.promfg.2015.07.496

[17] Jahandideh Z., Mirbaha B., Rassafi A. A.,"Identifying factors affecting pedestrians' crossing decisions at intersection in Iran". Proceeding of the institution of civil engineers- Municipal engineer, 172(1), 26-32, 2019. 
[18] Arsandrie, Yayi \& Prakoso, Anggita. "The Need of Pedestrian Footbridge to Promote Sustainable Living; Case Study: Footbridge Jln A Yani Pabelan, Kartasura," Civil Engineering and Architecture, Vol. 8, No. 4, 541-548, 2020. DOI: 10.13189/cea.2020.080418.

[19] Lenora Leuhery, Hamkah, "Determination of Black Site Area Based on Equivalent Accident Number Analysis: Case Study National Roads in Ambon City," Civil Engineering and Architecture, Vol. 8, No. 5, pp. 1063 - 1073, 2020. DOI: 10.13189/cea.2020.080533.

[20] Cantillo V., Arellana J., Rolong M.,"Modelling pedestrian crossing behavior in urban road: A latent variable approach". Transportation Research Part F, 32, 56-67, 2015, DOI: 10.1016/j.trf.2015.04.008.

[21] Yannis G., Golias J., Papadimitriou E.,"Modelling Crossing Behavior and accident risk of pedestrians". Journal of transportation engineering, 133(11), 634-644, 2007, DOI: 10.1061/(ASCE)0733-947X(2007)133:11(634).

[22] Wang Y., Peng Z., Chen Q.,"Simulated interaction of pedestrian crossings and motorized vehicles in residential areas". Physics A, 1046-1060, 2018, DOI: http://dx.doi.org/10.1016/j.physa.2017.08.138

[23] Mo Z.G, Mo. L.G.,"Study of pedestrian crossing behavior at signalized intersection based on structural equation model". Advance in Transportation Studies, an international journal, 2, 45-54, 2017.

[24] Comprehensive Mobility Plan (CMP 2018), National Institute of Technology, Patna.

[25] Yingying Ma, Siyuan Lu, Yuanyuan Zhang, "Analysis on Illegal Crossing Behavior of Pedestrians at Signalized
Intersections Based on Bayesian Network", Journal of Advanced Transportation, vol. 2020, ArticleID 2675197, 14 pages, 2020 DOI: https://doi.org/10.1155/2020/2675197

[26] Lund Adam, Lund Mark, "Mann-Whitney U Test using SPSS Statistics", Laerd statistics, https://statistics.laerd.co $\mathrm{m} /$ spss-tutorials/mann-whitney-u-test-using-spss-statistics. php (accessed August 20, 2019).

[27] Lund Adam, Lund Mark, "Kruskal-Wallis H Test using SPSS Statistics", Laerd statistics, https://statistics.laerd.com/spss-tutorials/kruskal-wallis-h-t est-using-spss-statistics.php (accessed August 20, 2019).

[28] Stephanie Glen. "Dunn's test: Definition" FromStatisticsHowTo.com: Elementary Statistics for the rest of us! https://www.statisticshowto.com/dunns-test/ (accessed September 18, 2020)

[29] James Lani "Bonferroni Correction", Statisticsolution: Advancement from clarity, https://www.statisticssolutions.com/bonferroni-correction/ (accessed on September 18, 2020)

[30] Hair, Joseph F. Multivariate Data Analysis. 6th ed. Upper Saddle River, N.J.: Pearson Prentice Hall, 2006.

[31] Granie M. A., Pannetier M., Gueho L.," Developing a self-reporting method to measure pedestrian behavior at all ages". Accident analysis \& prevention, 50, 830-839, 2013, DOI: 10.1016/j.aap.2012.07.009

[32] Yildirim, Z.,"Religiousness, conservatism and their relationship with traffic behavior", MIDDLE EAST TECHNICAL UNIVERSITY, 2007, http://citeseerx.ist.psu.edu/viewdoc/download?doi=10.1.1. $633.8093 \&$ rep $=$ rep $1 \&$ type $=$ pdf 